\title{
Curriculum Pearls for Faculty Members
}

\author{
Milena P. Staykova ${ }^{1, *}$ \\ ${ }^{1}$ Department of Nursing, Jefferson College of Health Sciences, Department of Nursing Research and EBP: Carilion \\ Clinic., Roanoke, VA, USA \\ *Corresponding author: Department of Nursing, Jefferson College of Health Sciences, Roanoke, VA. USA \\ Tel: 1-540-985-8261Ｅ-mail: mpstaykova@jchs.edu
}

Received: December 15, 2012 Accepted: February 21, $2013 \quad$ Online Published: April 25, 2013

doi:10.5430/jct.v2n1p74

URL: http://dx.doi.org/10.5430/jct.v2n1p74

\begin{abstract}
Many nurse educators fear involvement in curriculum development because of limited understanding of what it entails. Curricula, as etymological, epistemological, and phenomenological concepts have attracted the attention of educators for decades. Several curriculum models exist to explain curriculum decision-making, and the relationship among ideology, theory, and stakeholders. The Behavioral curriculum model reflects Western-society psychology, assuming that the environmental influences shape behaviors. Experientialism originated as open-minded theory, postulating that an experience led to creativity and helped a multiple intelligence development. Cognitive theorists analyze the curriculum through cognitive skills and acquisition of knowledge. The structure of disciplines attempts to explain the fundamental ideas about a specific subject or subjects in a discipline. Multiple stakeholders play key roles in curriculum decision-making from selection of curriculum models to implementation and evaluation. Curriculum specialists include planners, consultants, coordinators, directors, and professors. Educators are the largest group of professionals working in the realm of curriculum development. Frequently, instructors participate in curriculum planning under the supervision of a curriculum leader or other specialist. The supervisor is usually a person who works on three levels, instruction, curriculum, and staff development. Laypersons may include members of community and students. The role of members of the community has changed historically from passive to active participants in curriculum development. The curriculum pearls may help educators understand curriculum models or set a curriculum committee according to the mission and vision of an organization. In this review, the faculty will find fundamental elements connecting curriculum models, stakeholders, and nursing education.
\end{abstract}

Keywords: curriculum models; curriculum committee; nursing curriculum; faculty involvement in curriculum

\section{Introduction}

Curricula, as an etymological, epistemological, and phenomenological concept has attracted the attention of educators for decades (Posner, 2004; Wiles \& Bondi, 2007). Historically, defining the term "curriculum" led to discussions on how to develop universal education (Marsh \& Willis, 2003; Marshall, Sears, \& Schubert, 2000). Etymologically, the word curriculum originated from the Latin currere, meaning running course (Posner, 2004; Wiles \& Bondi, 2007). James (2009) explained the epistemology of curricula by examining the two complex relations. The first relation was based on the educational aims of formal knowledge defined in learning objectives and embedded in curriculum. The second relation connected the human factor such as teacher and student to the curricula. Defining the curricula phenomenologically as a set of courses has led to consensus that curricula were "a series of courses the student must get through" (Posner, 2004, p. 11). Curricula were considered a matrix of courses during the course of student's education.

Authors have been trying to define the concept "curriculum" for years; however, a single definition of curricula does not exist (Marsh \& Willis, 2003; Marshall, et al., 2000; Olivia, 2005; Posner, 2004; Wiles \& Bondi, 2007). According to Posner (2004), one single definition of curricula should not exist because "there is no panacea in education" but a "myriad curriculum alternatives" (p. 4). Posner suggested defining curricula by examining two levels of curriculum theoretical principals. The first level included the following seven concepts: a) scope and sequence, or series of intended learning or objectives; b) syllabus or course plan of study; c) content outline, or list of organized instructions (curriculum plan); d) standards, or ground work for the course with expected achievements 
and outcomes; e) textbooks, or day-to-day guide; f) course of study, or series of steps the student should complete (curricula); and g) all planned experiences.

The second level attempted to explain the nature and the meaning of a curriculum by integrating the following five curriculum concepts: a) formal curriculum, official or written; b) operational curriculum, active in practice; c) hidden curriculum, not acknowledged; d) null curriculum, not taught; and e) extra curriculum or teaching experiences occurring outside the school system (Posner, 2004). Each concept led to different interpretation and thereafter application of curriculum concepts (Posner, 2004). A competent educator should be cognizant of the coexisting concepts when designing comprehensive curricula for any type of organizations.

\section{Curriculum-Theory Models}

The curriculum studies started as a traditional theory intending to pass knowledge to people (deMarrias \& LeCompte, 1999) and were first influenced by Horace Mann and Henry Barnard. In 1893, the National Education Association established the Committee of Ten to look at the curriculum process. Dominant figures in the $18^{\text {th }}$ and $19^{\text {th }}$ century curriculum development were Johann Herbart, William Harris, Stanley Hall, John Sewey, Franklin Bobbitt, Harold Rug, and Ralph Tyler. This intellectual forum for curriculum policy making, influenced the curriculum development during early $20^{\text {th }}$ century and the contemporary society surpassing the influence of other curriculum-regulating groups (Marshal et al., 2007). Marsh and Wills (2003) favored models expressing curriculum decisions, and the relationship among theoretical principles, rules, and ideology. These models were traditional, social behaviorist, experientialist, constructionist, and structure of the discipline (Posner, 2004). See Figure 1 for a conceptual model.

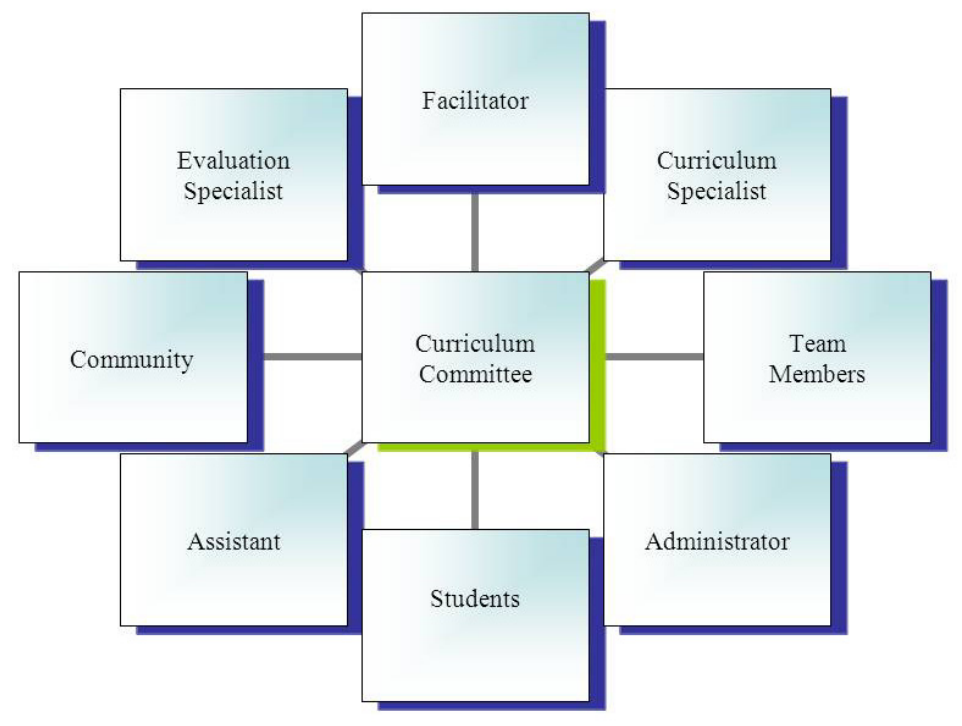

Figure 1: Members of Curriculum Committee

\subsection{Traditional Curriculum Model}

According to the traditional curriculum perspective, the purpose of education is to become a vector transmitting cultural heritage of a dominant culture (Posner, 2004). The curriculum of traditional education emphasizes a set of fundamental values and skills such as respect to authority, knowledge of fundamental terms, and socially accepted norms. Therefore, an official curriculum, representing the traditional position, selects educational objectives reflecting the values important for the dominant culture.

The traditional curriculum objectives may attempt to blend other cultures and ethnicity (Posner, 2004). The hidden curriculum (what is not taught but objectified in behavioral expectations) may have a damaging effect on the initial aims of the traditional curriculum and may lead to judgmental support of the dominant culture's ideology. For example, students who are not born in the dominant culture may face segregation based on language, skills, and other cultural or ethnic attitudes (Posner, 2004). The traditional curriculum usually includes strategies that educational institutions may use to promote the values of a central culture. Dewey, a leading critic of the traditional perspective, concluded that the traditional education was a result of passive transmission of information from the old to the new generations (Posner, 2004). Diverse student populations attend nursing schools and higher education institutions 
today. Faculty members selecting the traditional model for implementation in their programs should be aware of the limitations of the traditional curriculum model and should attempt to avoid teaching instruction biased mainly toward the governing culture.

\subsection{Behavioral Curriculum Model}

Behaviorist's model reflects Western-society's psychology. This model assumes that environmental influences shape student behavior. The behavior perspective is based on idea that the curricula should cultivate a set of skills, competencies, or processes directing a behavior toward performance objectives (Ediger, 2012; Posner, 2004); therefore, the official curriculum will emphasize objectives nurturing acceptable behaviors. Schunk (2004) contended "the hallmark of behavioral theories is not that they deal with behavior (all theories do that) but rather that they explain learning in terms of environmental events" (p. 2). The behaviorist approach, which has many supporters, has roots back to the ancient Greeks. Aristotle's realism served as a foundation for behaviorism (Posner, 2004). Ralph Tyler, a leading figure in the history of the curriculum development in 1960s represents the scientific approach to the curriculum that is still used by many educators (Posner, 2004). Tyler's work helps educators create a behavior-content matrix, curriculum plan or table of specification as an instrument for curriculum examination (Ediger, Posner, 2004).

Tyler based his quest to understand curriculum on fundamental questions leading to broad discussions. According to Tyler (1969), asking appropriate questions helped to formulate sound answers that in return led to establishing realistic objectives in the curriculum. Tyler (1969) noted that "many educational programs do not have clearly defined purposes" (p. 3) and compelled the educators to use intuitive sense rather than curriculum goals. School objectives should be matter of choices based on each school's philosophy. Tyler analyzed curriculum objectives by applying content and behavioral dimensions. For Tyler, education was "a process of changing the behavior patterns of people" (p. 5). Changing behavior included thinking, feeling, and acting the way educational institutions considered socially acceptable. For that reason, the curriculum planning should be based on selective criteria of what is taught and derived from the learning objectives (Halvorson, 2011).

Many contemporary social forces influence selecting acceptable behavioral norms and developing curriculum objectives (Waters, Rochester, \& Mcmillan, 2012). For instance in nursing, The Essentials of Baccalaureate Education for Professional Nursing Practice (American Association of Colleges of Nursing [AANC], 2008) led to revising core competencies in the curriculum objectives in many nursing programs. The modifications resulted in developing recommendations for learning objectives necessary to cultivate $21^{\text {st }}$ century nursing competencies such as globalization, culture, collaboration, and information technology. The nursing schools in the U.S. felt obligated to follow the AACN recommendations in order to prepare a competitive and competent healthcare workforce. In that manner, social forces have shaped the curriculum based on projected behavior of the future healthcare professionals.

\subsection{Experiential Curriculum Model}

Experientialism originated as open-minded theory, postulating that an experience may lead to creativity and problem solving skills, and may promote the development of multiple intelligences. According to the experiential perspective, experience is a result of an opportunistic educational momentum (Posner, 2004). Students' learning flourishes between the interactions of their physical and social environment and between their personal interests and experiences (Ediger, 2011; Posner, 2004). The curriculum developers have nominal influence in the student-centered curriculum; their main role is to facilitate the development of skills. For that reason, collaboration between educators and the students is instrumental in the selection of curriculum objectives.

The experiential perspective provides ground for unintentional learning (Posner, 2004). The primary learning objectives are results of the student's interests and needs but the educator's assumptions may direct what students learn. Students, for example, may want to learn about culture and ethnicity, but the educator may decide that learning about a specific culture (a favorite of the teacher) is more important than learning about another culture. Thus, basing the experiential curriculum on hidden and null curriculum concepts, the teachers may enforce their own beliefs (Alan, Smith, \& O'Driscoll, 2011; Posner, 2004). The hidden curriculum, suggested to be replaced by para-curriculum (Alan et al.) is often carried out through implicit messages and body language. The most frequent criticism of the experiential perspective is that an experience is difficult to classify and measure by standardized assessments tools (Posner, 2004).

John Dewey, father of the experiential education movement, has influenced the curriculum development in many ways (Nail, 2005). For instance, Dewey explained the curriculum using pragmatic philosophy and the progressive educational movement. Dewey believed reality was within the experience of the individual (Nail, 2005; Posner, 2004) and was a combination of continuity and interactions among the past, present, and future. Therefore, educators 
needed to create learning environment for developing problem-solving skills that reflect student needs and interests (Ediger, 2011).

The theory of experiential education has many implications in nursing education, especially in clinical sessions. Creating curricula to reflect clinical experiences is a complex process and is based on approaches of interaction and continuity that create specific momentum in which the past, present, and future knowledge of student and faculty converge (Nail, 2005). For, example, analyzing a blood pressure under faculty supervision integrates (a) past student knowledge of normal and abnormal ranges (didactic objective reflecting past learning), (b) present blood pressure values obtained from a patient, and (c) future encounters of blood pressure analysis (interaction). The momentum facilitates the development of blood pressure competencies leading to safe nursing practice (continuity). Furthermore, a professional socialization occurs through para-curriculum where clinicians or nurse-mentors act as gatekeepers to transforming academic knowledge into clinical competencies (Alan et al., 2011).

Dewey was not content with traditional education and frequently criticized its principles. According to Nail (2005) "Dewey criticizes traditional education for lacking in holistic understanding of students and designing curriculum overly focused on content rather than content and the process which is judged by its contribution to the well-being of individuals and society" (para. 4). For example, standardized testing measuring the student's academic performance has focused on the content rather than the process of individual knowledge and social value acquisition. Therefore, establishing educator competencies in curriculum design may help in evaluating the student preparation and academic experiences comprehensively, and consequently the specific program plan.

\subsection{Constructivist Curriculum Model}

Cognitive theorists analyzed the curriculum through the nature of cognitive skills concentrating on acquiring knowledge in a constructivist perspective. The constructivist perspective aimed to explain the curriculum through cognitive elements such as schemata and cognitive operations (Posner, 2004). For constructivists, the primary purpose of education is to develop the human mind (Posner, 2004). Constructivists believe thinking and reasoning are internal processes. The assumption leads to individually preconceived notions that are the result of the student's own cognitive experiences, reasoning, and perception (Posner, 2004). For instance, if a student considers that a critical care class is more important than pharmacology, the student may focus mainly on developing knowledge and skills in critical care and ignore learning competencies in pharmacology. Having the student self-prioritize learning needs may lead to fixations limiting the appreciation and development of new knowledge.

Historically, constructivism originated from the classical Greek philosophy. Plato supported idealism, in which the mind or sprit explained everything that exists (Gredler, 2005). Furthermore, knowledge was an outcome of concepts and ideas; knowledge was innate or an inborn characteristic (Gredler, 2005). Plato's philosophy guided the cognitive movement and prepared the ground for the constructivist perspective of the nineteenth century advocated by philosopher Emanuel Kant. Later, Jean Piaget, Noam Chomsky, and Richard Anderson founded the modern constructivist position in education.

A limitation of the constructivist perspective came from the incomplete scope of content and the individual subjectivity (Posner, 2004). For example, a constructivist approach is found in selecting didactic and clinical components of the nursing education. The professional nursing training evolves through continuous research and as a result of federal and state regulation; however, the content taught in a classroom and clinical settings is limited to the faculty competencies to select learning objectives that lead to developing knowledge, attitudes, and skills necessary to prepare successful nursing graduates (Poindexter, 2008).

\subsection{Structure of the Disciplines Curriculum Model}

The structure of disciplines aims to explain the fundamental ideas about a specific subject or several subjects in a discipline. For example, the nursing discipline integrated many subjects ranging from pediatrics, obstetrics, and gerontology to genetics and genomics, information technology, and community. These subjects are specific for the nursing education. According to the structure of the disciplines, the purpose of education is to develop the human intellect and knowledge based on main ideas in specific academic area (Ediger, 2011; Posner, 2004). The epistemology of those curricula is based on an outcome of "fundamental ideas of the discipline" (Posner, p. 99) in which the student is seen as an investigator. In this curriculum model, opportunities for bias, incompetence, lack of rigor, heuristic relevance, preciseness, missing information, and data manipulation exist based on the subjective inquiry (Posner, 2004). The structure of disciplines serves a specific discipline because key content is chosen to satisfy specific academic objectives; therefore, this curriculum model requires special considerations and insightful understanding of its complex framework. The language used to describe the fundamental concepts of a specific discipline may be too 
abstract, scholarly, or otherwise perplexing for students coming from low socioeconomic or ethnically diverse backgrounds who have not been exposed to higher academic standards (Ediger, 2011; Posner, 2004). According to Posner, the structure of disciplines is a curriculum model suitable for academically oriented students pursing advanced education. Educators with abstract knowledge and skills and advanced educational preparation should be involved in this curriculum decision-making and then teach the curricula.

Educational critics of the 1950s provided the theoretical foundation of the structure of disciplines (Posner, 2004). The critics refocused the curriculum objectives on subject matter and the disciplines of knowledge; as a result they promoted rigorous academic education (Posner, 2004). As an advocate of this curriculum model, Max Beberman formed a group of supporters to improve the mathematics curriculum in high school. Another proponent, Jarrold Zacharia and a group of scientists evaluated the priorities in the curricula and realized the scientific subject matter was beyond knowledge exposition (Posner, 2004, p. 56). For example in healthcare, the nursing discipline has developed distinct competencies ranging from the cognitive skills and critical thinking such as nursing process of assessment, planning, implementation, and evaluation to psychomotor skills proficiency such as injection administration and wound care. The nursing knowledge may be difficult to understand by other disciplines if their curricula diverged from the healthcare focus. Based on Zacharia's work, Jerome Bruner concluded that each discipline needs to conduct its own inquiry because the "subject matter is dynamic and something evolving, instead of given" (Posner, 2004, p. 56). Bruner highlighted the saliency of the structure of knowledge (Ediger, 2011, p. 174). Nursing research and evidence-based practice help educators to investigate issues specific for the discipline. The structure of disciple curricula is seen as abstract and multifaceted (Posner, 2004) and it is unique to different professional specialties. Nurse educators may benefit from this curriculum model aiming to develop high cognitive skills and outcome measures specific to the nursing discipline.

\section{Key Stakeholders in the Curriculum Development}

Designing curricula requires a multidisciplinary approach (Diamond, 2008). Gordon (2004) confirmed curriculum development was a group effort. Many individuals needed to participate in curriculum activities to generate "psychological ownership of the resulting program" (Olivia, 2005, p. 33). Limited information was found during the literature review on characteristics and role expectations of the curriculum committee members. Diamond (2008), emphasizing the selection of the curriculum team members should receive serious consideration, recommended that a group of stakeholders should participate in the curriculum development. Suggested stakeholders included facilitators, teams of faculty members, administrators, graduate assistants, students, and evaluation specialists (see Figure 2).

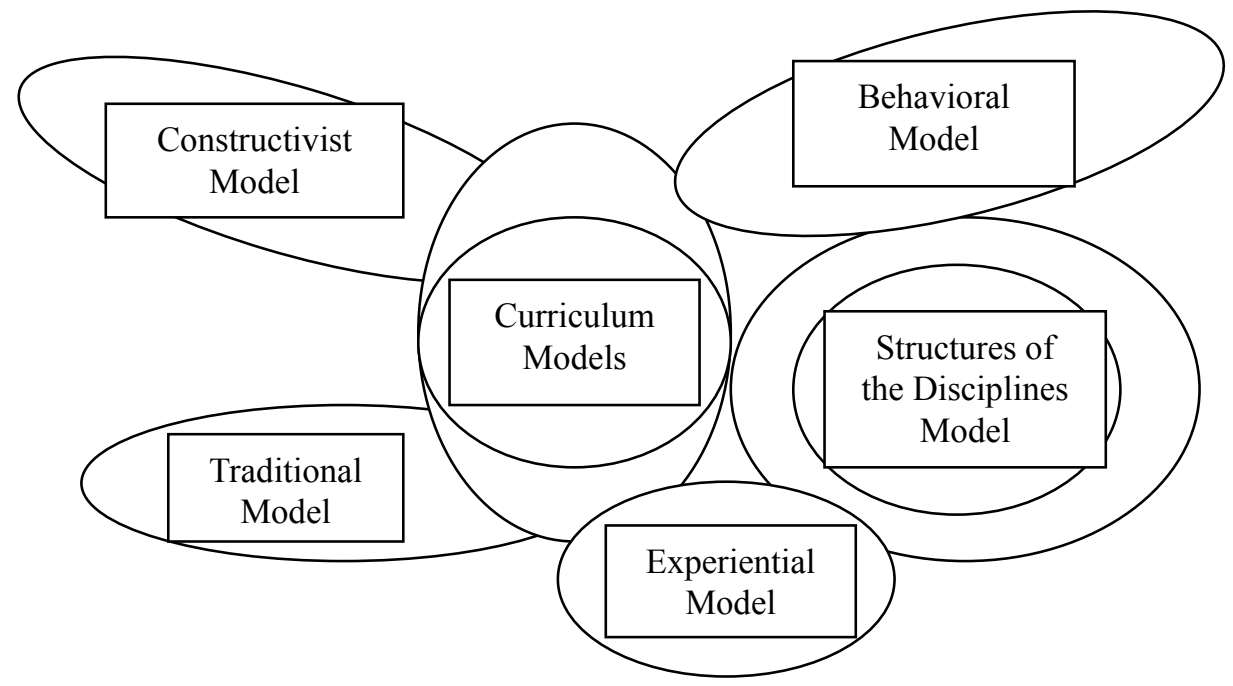

Figure 2: Cluster of Curriculum Models

Curriculum planning should be a cooperative endeavor and curriculum improvement should come from the collaborative decision-making of the stakeholders (Olivia, 2005, Waters et al., 2012). Olivia (2008) suggested the following array of curriculum workers to participate in the curriculum process: curriculum specialists, educators, supervisors, and laypersons. Curriculum specialists included planners, consultants, coordinators, directors, and professors. Educators were the largest group of professionals working in the realm of curriculum development. Most 
often, teachers participated in curriculum planning under the supervision of a curriculum leader or other specialist. The supervisor was usually a person who worked on three levels, instruction, curriculum, and staff development. Laypersons included the members of community and the students. The role of members of the community has changed historically from passive to active participants in curriculum development (Olivia, 2005). Participating directly or indirectly in curriculum development, students provided input, participated in curriculum committees, answered surveys, or offered suggestions on curriculum development and improvement. Merging the perspectives of Diamond (2008) and Olivia (2005) during curriculum selection, curriculum leaders should identify key curriculum-committee stakeholders important to curriculum development.

\subsection{Roles of the Curriculum Members: Facilitator}

A curriculum facilitator may serve as a chair of a curriculum committee or as team leader (Diamond, 2008). The facilitator may be a dean, departmental chair, nursing program director acting as an administrator, curriculum leader, or instructional leader. A facilitator assumes roles of direct or indirect leadership; his or her role depends on leadership style and degree of involvement. A facilitator, acting as a chair or a team leader, needs to have expertise and skill to coordinate group activities (Diamond, 2008). The chair of curriculum committee holds the authority to recommend or approve the curriculum, coordinate effective teamwork, and ensure positive outcomes in the curriculum development (Diamond, 2008). The facilitator as a chair of the committee is a key figure in the curriculum process and requires careful selection.

\subsection{Team of Faculty Members}

A team of faculty members is usually selected from a pool of educators who are known as experts in the field or people who are involved with teaching. Educators are the major components in curriculum development (Olivia, 2005). According to Fitzpatrick and Tanner (2006), faculty members have historical role in curriculum development. Diamond (2008) recommends the team of educators to include individuals from the major academic programs or departments involved in curriculum planning. However, when the curriculum design requires more than eight faculty members, a smaller group organized as a steering committee, may increase the effectiveness of the team (Diamond, 2008).

The process of curriculum development requires fundamental knowledge and understanding (Keating, 2006). Nurse educators involved in the curriculum process should know how to assess, design, implement, analyze, and evaluate curriculum (Keating, 2006). The curriculum members need to be aware of future trends of the nursing profession when they design curriculum. Furthermore, curriculum developers should be familiar with legal issues driving curriculum changes (Waters et al., 2012). For these reasons, ongoing training is necessary to prepare faculty members to handle curriculum development (Billings \& Halstead, 2005; Keating, 2006).

Leadership at educational institutions should involve as many educators as possible in the process of planning and designing curriculum (Olivia, 2005). Giving the educators opportunities to perform tasks according to their abilities and experience may help them commit to the process of curriculum design. Wolters and Daugherty (2007) found "teachers' sense of efficacy refers to individuals' judgments or beliefs regarding their ability to accomplish critical instructional tasks" (p. 181). Therefore, increasing an educator's confidence in curriculum development plays a significant role in the strategy to involve nurse educators in the local curriculum committee.

\subsection{Roles of the Curriculum Members: Curriculum Specialist}

A curriculum specialist holds the responsibility to transform theory into practice (Olivia, 2005). The curriculum professional works collaboratively with educators to innovate or improve curriculum and instruction. The specialist should reviews each step of the curriculum process, from developing a school's philosophy to assessment, planning, designing, implementation, and evaluation. The specialist has opportunities to encourage research on curriculum issues. Moreover, the curriculum specialist should assist educators in their decision-making by observing the dynamics of the local educational institutions.

\subsection{Roles of the Curriculum Members: Evaluation Specialists}

An evaluation specialist collects and interprets data, and evaluates the results of the curriculum products (Diamond, 2008). Two forms of evaluation providing grounds for data generation are formative and summative assessments. In formative assessment, data are collected throughout the year; in summative assessment, data are collected toward the end of the school year. Both forms involve evaluating a student's achievement and performance (Diamond, 2008). The collected information provides ground for evaluating the instructional program and planning future objectives. Curriculum-based formative assessments supply the educators with feedback, help them evaluate the curriculum, and improve their classroom instructions in consensus with standards (Fewster \& MacMillan, 2002). According to Thurlow (2000), the summative assessments involve collecting data toward the end of the school year to evaluate the 
student's achievement.

Lack of educator training or lack of assessment ownership leads to ignoring important data (Diamond, 2008). Making educators a part of curriculum development and training them how to evaluate data should eliminate the problem. Diamond (2008) contended effective data collection led to improved curriculum quality. Evaluation specialists are key constituents in curriculum development, as they are responsible for communicating data among the curriculum committee members (Diamond, 2008).

\subsection{Roles of the Curriculum Members: Students}

Students participated directly or indirectly in the curriculum process. In recent years, student involvement in the curriculum changed because of increased movement toward student rights. For example, according to Woods "a curriculum for democratic empowerment engages students in choices about and control over the most central element of their school experience- the curriculum itself" (as cited in Olivia, 2005, p. 92). In many school systems, student representatives are active members of the curriculum team. Students are "naturally interested in the planned curriculum changes and what the changes would mean for them" (Iwasiw et al., 2005, p. 244). Depending on their level of maturity, students may serve as curriculum committee members and provide direct input. Students may share with curriculum members their perceptions regarding curriculum implementation; they may communicate the curriculum decisions to the rest of the student body. The students may participate in surveys or offer indirect suggestions through student leaders, and they may assist in carrying out designated tasks, such as copying and distributing materials (Olivia, 2005).

\subsection{Roles of the Curriculum Members: Community}

Members of the community bring many benefits and facilitate the curriculum process (Olivia, 2005). Community members' participation may range from serving as advisory committee members to serving as resource persons and volunteer aides. The community stakeholders are faculty members from other disciplines, alumni, educators from the local school system, healthcare leaders, community leaders, "as well as members of professional bodies" (Iwasiw et al., 2005, p. 18). Many community members participate in surveys and provide feedback on particular issues (Olivia, 2005). Furthermore, community members are instrumental in reviewing instructional materials and textbooks for bias and distortion, student competencies in diverse health care setting, and safety issues affecting clinical practice of the students. A curriculum leader may have better success designing new curriculum with community support (Iwasiw et al., 2005; Olivia, 2005). Moreover, when members of the community think that their opinions are valued, they may commit readily to curriculum development. The role of community members has evolved positively over the historical span of the educational development. In the past, a communication gap existed; "an invisible wall was erected between the community and school" (Olivia, 2005, p. 92). A tendency to close the gap is a current phenomenon with community support ranging from fundraising activities and publishing local newspapers and bulletins to e-mail announcements, and other communications helping to build community-education relationships (Olivia, 2005).

\section{Levels of Educators' Involvement in Curricula}

Educators' involvement in curriculum development is critical for developing competencies in curriculum decision-making. Research studies have demonstrated that faculty involvement in curriculum planning has positive effects on nursing graduate performance at licensure examinations and successful student integration in professional practice (Oermann \& Heinrich, 2005; Morris \&Hancock, 2008). Tanner and Tanner (2006) discussed three levels of educators' involvement in curriculum development: Level 1, Imitative Maintenance; Level 2, Mediative; and Level 3, Creative-Generative. The three levels corresponded to Benner's novice, competent, and expert nurse. In the first level, the teacher's focus was on maintaining the existing curriculum. Educators base their practice on textbooks, follow routine activities, and use ready-made materials without critically evaluating the content. Such practice leads to cultivating single skill instead of holistic learning (Glickman, Gordon, \& Ross-Gordon, 2006). According to Glickman et al., educators at the first level are left alone and must struggle with their responsibilities if institutions undertake curriculum change. At the first level, teachers display little interest in curriculum innovation because of their lack of experience (Glickman et al., 2006).

A characteristic of mediative level is the awareness of the need to blend curriculum content with social issues. Adaptation, accommodation, and adjustment with a focus on immediate situations are specific characteristics of the level (Glickman et al., 2006). An example is integrating disaster preparedness activities into the current curriculum

following a terrorist attack event. At the mediative level teachers use resources, adapt research findings, and include the stakeholders in the curriculum process. The educators are interested in new ideas and in improving existing practices. 
Educators at the third level commit to curriculum development. They approach the curriculum on macro levels, examining its horizontal and vertical alignments (Diamond, 2008). Horizontal alignment involves concepts transferred throughout all the subjects in a program (Diamond, 2008). Vertical alignment refers to concepts transferred from one semester to another (Diamond, 2008). At the third level, teachers conduct research by experimenting in the classroom, using creative approaches, and sharing their finding with colleagues (Glickman et al., 2006).

\section{Conclusions}

The need for healthcare professional's "competency" as demanded by the diverse and continuously advancing healthcare system impacts the curriculum framework; it is a driven force for changes in curriculum (Davenport, Spath, \& Blauvelt, 2009). Nursing faculty members often lack proficiency and curriculum competencies due to the clinical blueprint of the nursing education which focus on theory and practice and seldom curriculum education. Curriculum concepts are predominantly taught at programs granting graduate degrees in education; however, many nursing faculty have a clinical background preparation. Nurse educators want to become competent in curriculum decision-making. Nagy (2002) underlines that "curriculum materials are the backbone of practitioner practice" (p. 31). Curriculum knowledge, in a hopeful manner, will equip the nursing faculty with skills to create meaningful learning experiences. The foundation of a comprehensive curriculum is based on curriculum models, philosophies, and guiding principles (Daventport et al., 2009). Faculty members who feel empowered by curriculum development may feel able to create courses and design instructional activities aiming for quality of education. The curriculum pearls are useful resources to a novice faculty when selecting a curriculum module or creating a curriculum committee. The content in the pearls may help a seasoned educator who is attempting a curriculum review, which is both tedious and creative (Davenport et al., 2009).

Researchers have paid considerable attention to the competencies of nurse educators and their educational preparation (SREB, 2002). In response to the growing demands for nursing faculty members, the curriculum pearls may serve clinical nurses who have embraced the educators' role with a brief but informative outline of curriculum models available for implementation in the nursing curricula. This synopsis delineates the expectations for educators as well as their role as curriculum committee members; these expectations are often vague for faculty members willing to take active part in curriculum planning. Finally, the curriculum pearls may serve as an evaluation tool when reviewing educational programs through the lenses of curriculum-theory models.

\section{Acknowledgements}

The author would like to acknowledge the valuable contributions of Drs. Don Bronsard, Carol Molinari, and John Jonson for providing feedback on the document as it was being developed. The author would like to thank Mrs. Leslie Block for her editing service and Ms. Rhoda Murray for final proof reading.

\section{Conflict of Interest}

The author declares no conflict of interest.

\section{References}

Allan, H., Smith, P., \& O'Driscoll, M. (2011). Experiences of supernumerary status and the hidden curriculum in nursing: a new twist in the theory-practice gap. Journal of Clinical Nursing, 20(5-6), 847-855. http://dx.doi.org/10.1111/j.1365-2702.2010.03570.x

American Association of Colleges of Nursing. (2008b, October 20). The essentials of baccalaureate education for professional nursing practices. Washington, DC: Author.

Billings, D. M., \& Halstead, J. A. (2005). Teaching in nursing: Guide for faculty (2 ${ }^{\text {nd }}$ ed.). St. Lois, MO: Elsevier.

Davenport, N., Spath, M. L., \& Blauvelt, M. J. (2009, July/August). A step-by-step approach to curriculum review. Journal of Nurse Educator, 34(4), 181-185. http://dx.doi.org/ 10.1097/NNE.0b013e3181aaba80

Diamond, R. M. (2008). Designing and assessing courses and curricula: A practical guide ( $3^{\text {rd }}$ ed.). San Francisco, CA: Jossey-Bass.

Ediger, M. (2012). Recent leaders in American education. College Student Journal, 46(1), 174-177. Retrieved from EBSCO host database.

Fewster, S., \& MacMillan, P. D. (2002). School-based evidence for the validity of curriculum-based measurement of 
reading and writing. Remedial and Special Education, 23(3), 149 -156. Retrieved from EBSCO host database.

Gordon, S. P. (2004). Professional development for school improvement: Empowering learning communities. Upper Saddle River, NJ: Pearson.

Gredler, M. (2005). Learning and instruction: Theory into practice (5th ed.). Upper Saddle River, NJ: Prentice Hall.

Halvorson, M. (2011). Revealing the technological irresponsibility in curriculum design. Curriculum Inquiry, 41(1), 34-47. http://dx.doi.org/10.1111/j.1467-873X.2010.00523.x

James, M. (2009, November 1). How the conception of knowledge influences our educational practices: Toward a philosophical understanding of epistemology in education. Philosophy Scholarship, Paper 13. Retrieved from EBSCO host database.

Keating, S. B. (2006). Curriculum development and evaluation in nursing. Philadelphia, PA: Lippincott Williams \& Wilkins.

Keating, S. B., Rutledge, D. N., Sargent, A., \& Walker, P. (2003). California examines definitions of competency. Patient Care Management, 19(4), 7-10. Retrieved from EBSCO host database.

Kozier, B., Erb, G., Berman, A., \& Snyder, S. J. (2008). Fundamentals of nursing practice: Concepts, process, and practice $\left(8^{\text {th }}\right.$ ed.). Upper Saddle River, NJ: Prentice-Hall.

Iwasiw, C., Goldenberg, D., \& Andrusyszyn, M. (2005). Curriculum development in nursing education: An integrated framework. Sudbury, MA: Jones and Bartlett.

Marsh, C. J., \& Willis, G. (2003). Curriculum: Alternative approaches, ongoing issues ( $3^{\text {rd }}$ ed.). Upper Saddle River, NJ: Pearson.

Marshall, J. D., Sears, J. T., \& Schubert, W. H. (2000). Turning points in curriculum: A contemporary memoir. Upper Saddle Creek, N.J.: Prentice Hall.

Morris, T., \& Hancock, D. (2008). Program exit examination in nursing education: Using a value added assessment as a measure of the impact of a new curriculum. Educational research Quarterly, 32(2), 19-29. Retrieved from EBSCO host database.

Nail, J. (2005, March 28). Summary of J. Dewey's “Experience \& Education. In Dewey, J. Experience and Education. Macmillan. Retrieved from EBSCO host database.

Nagy, S. (2002). Using theory in curriculum development: The future selves curriculum. American Journal of Health Studies, 18(1), 31. Retrieved from EBSCO host database.

Oermann, M. H., \& Heinrich, K. (2005). Annual review of nursing education. Volume 3. Strategies for teaching, assessment, and program planning. New York: Springer.

Olivia, P. F. (2005). Developing the curriculum (6 ${ }^{\text {th }}$ ed.). Boston, MA: Pearson Education, Inc.

Poindexter, K. A. (2008). Essential novice nurse educator role competencies and qualifications to teach in a pre-licensure registered nurses education program. (Doctoral Dissertation, Western Michigan University, 2009). Retrieved from ProQuest Digital Dissertations. AAT 3316931.

Posner, G. J. (2004). Analyzing the curriculum ( $3^{\text {rd }}$ ed.). New York: McGraw Hill

Schunk, D. (2004). Learning theories: An educational perspective ( $4^{\text {th }}$ ed.). Upper Saddle River, NJ: Prentice Hall

Thurlow, M. L. (2000). Standards-based reform and students with disabilities: Reflections on a decade of change. Focus on Exceptional Children, 33(3), 1 -26. Retrieved from EBSCO host database.

Tyler, R. W. (1969). Basic principles of curriculum and instruction. Chicago, ILL: University Of Chicago Press.

Waters, C., Rochester, S., \& McMillan, M. (2012). Drivers for renewal and reform of contemporary nursing curricula: A blueprint for change. Contemporary Nurse: A Journal for the Australian Nursing Profession, 41(2), 206-215. http://dx.doi.org/10.5172/conu.2012.41.2.206

Wiles, J., \& Bondi, J. (2007). Curriculum development: A guide to practice (7th. ed.). Upper Saddle River, NJ: Prentice Hall.

Wolters, C., \& Daugherty, S. (2007). Goal structures and teachers' sense of efficacy: Their relation and association to teaching experience and academic level. Journal of Educational Psychology, 99(1), 181-193. http://dx.doi.org/10.1037/0022-0663.99.1.18 